\section{CARMEN DE BURGOS Y RAMÓN GÓMEZ DE LA SERNA}

\author{
Antonio Ubach Medina \\ Departamento de Filología Española III \\ Facultad de Ciencias de la Información \\ Universidad Complutense de Madrid \\ Avda. Complutense, $s / n$ \\ 28040, Madrid \\ ubach@ccinf.ucm.es
}

\section{CARMEN DE BURGOS AND RAMÓN GÓMEZ DE LA SERNA}

\begin{abstract}
Carmen de Burgos, born in the southern province of Almeria, arrives to Madrid at the beginning of the $20^{\text {th }}$ century. She has decided to maintain her independence after an unhappy marriage and to earn her bread with her writings. She also uses them to promote different social issues, her idea of literature and the young writers who are starting their careers. Ramón Gómez de la Serna, twenty years her younger, meets her in 1908, when he is starting his career. Carmen represents the ideal woman he describes in his conference titled "The New Literature". Along the next twenty years they share their lives, travels and writing in a rich partnership that ends suddenly in 1929 after the short flirt of Carmen's daughter with the writer.
\end{abstract}

KEY WORDS: Carmen de Burgos; Colombine; Ramón Gómez de la Serna; Revista Crítica; Prometeo; literary relationship.

Carmen de Burgos nace en Almería en 1867 (Núñez, 2005: 26). Su padres, que se llevaban once años de edad, poseían tierras en la provincia. Las familias de estos habían desempeñado un papel relativamente importante en la historia local de la época. "La familia de Carmen perteneció [...] a la pequeña burguesía que aspiraba a consolidar su posición e intentaba alcanzar relevancia y protagonismo social" (Núñez, 2005, 29). Ramón Gómez de la Serna, el otro protagonista de esta intervención, nace en el verano de 1888', en el Madrid de la Restauración, en una familia burguesa con conexiones políticas importantes ${ }^{2}$, lo cual le hace vivir muy de cerca los avatares del país. La diferencia de edad entre ambos es, pues, de veinte años. De lo que se tratará aquí es de ver cómo se desarrolló el comienzo de la relación entre estos dos escritores en la España de principios del siglo XX, en un época en la que esa diferencia de edad, siendo mayor la mujer, no dejaba de provocar todo tipo de comentarios, incluso en una ciudad grande como Madrid.

Tras la desaparición del Ministerio de Ultramar, en el que trabajaba el padre de Gómez de la Serna, en 1898, la fa-
RESUMEN: Carmen de Burgos, proveniente de la sureña provincia de Almería, llega a Madrid a principios del s. XX, decidida a mantener su independencia tras un desdichado matrimonio y a ganarse la vida escribiendo, apoyando una serie de causas sociales, su idea de la literatura y los jóvenes valores. Ramón Gómez de la Serna, veinte años más joven que ella, la conoce en 1908, cuando comienza su carrera literaria. Carmen encarna el ideal de mujer que describe en su conferencia sobre "La nueva literatura". Durante veinte años comparten vida, viajes y escritura en una fructífera compañía que termina bruscamente en 1929 tras la relación fugaz de la hija de Carmen con el escritor.

PALABRAS CLAVE: Carmen de Burgos; Colombine; Ramón Gómez de la Serna; Revista Crítica; Prometeo; relación literaria.

milia se traslada a vivir a la provincia de Palencia, donde el cabeza de familia fue destinado como registrador de la propiedad. Ramón y uno de sus hermanos se incorporan como alumnos internos a un colegio de Palencia, del que no guarda buenos recuerdos ${ }^{3}$, continuando la educación que ya habian iniciado en Madrid. Alli se inicia su vocación como escritor:

Afortunadamente, al año siguiente el internado tuvo el optimismo del colegio nuevo, y en aquel contraste lleno del espíritu inmortal de Castilla la Vieja, saturado del deseo de serenidad que es el escribir, sentí la vocación de mártir que había de formar mi vida literaria.

Un cuaderno tuvo la culpa, otro cuaderno la hizo empedernida, y otro me hizo dar el paso trascendental (Gómez de la Serna, 1948, 113).

En esta evocación que hace del inicio de su oficio, ya que este fragmento pertenece a la autobiografía que escribe en su madurez, hay algunos elementos que son dignos de señalar. En primer lugar, el lugar donde se produce el 
comienzo de su tarea, Castilla, donde nace la lengua en la que se va a expresar. En segundo lugar, la utilización del término mártir para referirse a esa profesión, con lo que supone de sacrificio personal. Por último, y a la vez, la felicidad que esa tarea, que va a suponer un esfuerzo, reporta simultáneamente al trabajo, como muestra la transformación que en su visión del internado provoca la nueva actividad.

La familia pasa tres años alejada de la capital y, tras obtener su padre un puesto de diputado, vuelven a Madrid en 1901. Así describe el autor el regreso: "jFeliz vuelta como yendo a recuperarlo todo, y ya en el alma la luz de Castilla que me había permitido estar en el pueblo dándome la 'sobre-luz' que necesita el castellano nuevo para romper a hablar con soltura!" (Gómez de la Serna, 1948, 119).

En los años de su estancia en el colegio de los Escolapios, y luego del Instituto San Isidro, se inicia su precoz relación con el periodismo: comienza a elaborar El Postal, periódico de 25 ejemplares de tirada del que es casi único redactor, y además copista a mano ${ }^{4}$. Esa vocación está basada en "mi fe en el explorar el pensamiento sobre cualquier sacrificio o incomodidad" (Gómez de la Serna, 1948, 113). La conciencia del esfuerzo que supone la tarea que se propone se le hace patente desde muy joven, no solo por las horas que le ocupa, sino por la incomprensión sobre la labor que realiza.

Ramón vive en el ámbito protegido de la burguesía acomodada. Sus aficiones e inquietudes son apoyadas por su padre, desde los primeros artículos aparecidos en la prensa de provincias hasta su primer libro, Entrando en fuego, que se publica en 1905. Lo recuerda así: ¿¿ué he hecho? ¿Adónde voy a parar? ¿Por qué esa impaciencia de dar un libro a los dieciséis años? Ricardo Baeza -mi condiscípulo desde el Instituto- dijo: 'Entrar en fuego... y salir escaldado'" (Gómez de la Serna, 1948, 182).

Sobre esa impaciencia, que asocia con el período de la adolescencia, reflexiona en su autobiografía, recordando su apasionamiento en todas las direcciones de la vida. Le acabó de apartar por completo de la política el episodio en el que fue detenido por reventar un mitin de socialistas y republicanos en el Retiro. El padre intervino para paliar las consecuencias. Ese aspecto de la política vivido en la rebeldía de la adolescencia tenía su contrapartida en el que era el ámbito habitual de la vida familiar por los cargos de su padre, que también provoca su rechazo.

El rechazo al mundo de la política es también un rechazo al mundo de la literatura que se está haciendo en esos momentos de su despertar a la vida, como refleja una carta que Carolina Coronado ${ }^{5}$, pariente del autor, escribe al leer sus primeros artículos publicados en La Región Extremeña y El Adelantado de Segovia, en la que dice, entre otras cosas:

Nosotros no podemos reír de lo que escriben esos niños "crepitantes" y "dinamitantes" que han invadido las prensas "modernizantes". Es demasiado triste lo que pasa y debemos, yo no puedo, sino tú, usar de tu influjo para evitar cuanto se pueda esa verdadera calamidad de familia (Gómez de la Serna, 1948, 168).

\section{El primer viaje a París}

Del colegio de los Escolapios pasa al Instituto. En 1905, al acabar este marcha diez días a París con el escaso dinero que le da su padre. Ramón no puede substraerse a la fascinación que París ejercía desde hacía un siglo sobre la intelectualidad española, y esta primera experiencia en la ciudad, que se repetirá varias veces, es la que deja una huella más perdurable: "El París de entonces es el que más he visto siempre, aunque después haya vuelto en mejores condiciones y por mucho más tiempo" (Gómez de la Serna, 1948: 179).

Allá ha descubierto un mundo que satisface mucho más que su realidad cotidiana sus propias aspiraciones. Pero es un mundo que está más lejos que la distancia geográfica que separa a la capital francesa de la española. Ramón descubre allá la modernidad y el arte nuevo que está inundándolo todo. "Tras su primer viaje a París (...), Ramón echaba seguramente en falta también la existencia de galerías de arte, de sitios donde se expusiera el arte nuevo, tan trepidante ya en París" (Zlotescu, 1987, 27).

Si antes de partir ya se sentía ajeno a lo que le rodeaba, tras su regreso ese extrañamiento se agudiza: "Ramón era, ante todo, un cosmopolita arraigado en un Madrid fundamentalmente paleto" (Brihuega, 1981, 184). Si hasta 
entonces el rechazo al mundo familiar le había hecho refugiarse en esa temprana e incipiente vocación de escritor, pronto descubre que en ese ámbito también existen los obstáculos y la incomprensión a su modo de entender el arte.

Ingresa en la Universidad para cursar la carrera de Derecho, dentro de la tradición de su familia. Ese momento coincide con el de la publicación de Entrando en fuego (1905) y a estas alturas sus intereses auténticos ya están claramente definidos. No van por el camino del Derecho, y aunque acaba la carrera nunca llegará a ejercerla, a pesar de las ofertas que recibe a través de su padre desde el mundo de la política. Sabe que está pagando un precio, pero que es necesario para lo que se propone: "Teorizar y escribir en la independencia fue el ideal querido de aquellos años y ser en medio de todo eso un hombre de honor al que no se atreviese a proponerle nadie nada indecoroso" (Gómez de la Serna, 1948, 202).

\section{Prometeo}

1908 es un año clave en la trayectoria literaria del autor. Acaba sus estudios universitarios. Ese año empieza a publicarse la revista Prometeo, que crea y dirige su padre, y que tratará de cultura y política, materia sobre la que siempre hay un artículo firmado por su progenitor. Este tiene ya un medio para tratar de traer esa modernidad que le ha deslumbrado en París. Pero es también un año clave por otros motivos: empieza a frecuentar la tertulia que Carmen de Burgos celebra en su casa. Dice Concha Núñez (2005, 186) sobre ella:

El proyecto soñado es atraer la vida artística e intelectual al salón ameno, en el que hombres y mujeres comparten ideas y proyectos, lejos de la bohemia de la calle, y abrir las puertas a las jóvenes promesas que merecieran ser escuchadas por las figuras consagradas para alentar toda voz original.

Ramón es uno de los atraídos, pues se trata de una de esas jóvenes promesas. Como consecuencia de sus actividades en el mundillo literario, es nombrado secretario de la sección de literatura del Ateneo. En el ejercicio de sus funciones como tal presenta allí, para su discusión, una memoria titulada "El concepto de la nueva literatura", ocasión que, como cuenta en Automoribundia, acabó en un escándalo. La lectura de esta "memoria" y el rechazo que suscitaron las ideas que contenía terminaron de la siguiente manera: "A la tercera sesión de discusión de la memoria, se celebró el guirigay sin presidencia, y la cuarta vez los bedeles se negaron a encender el salón" (Gómez de la Serna, 1948, 192).

El texto de la memoria fue primero publicado en el número VI de Prometeo, de abril de 1909, y posteriormente en una separata de la revista. De este modo utiliza también esta tribuna para difundir las ideas que entonces cree necesarias para modernizar el mundo literario español.

Gómez de la Serna comienza rechazando la literatura que se está escribiendo en esos momentos en España, la de los autores de la generación del 98. Aboga por una literatura arraigada en la vida, en lo actual. Subraya la influencia de Nietzsche y su panteísmo, ya que la labor del filósofo ha sido expresar las ideas contemporáneas, resultado de la evolución humana, en el lenguaje que corresponde a la época y liberarlo de las ideas previas. La literatura es una forma de conocimiento que debe seguir su propio camino. Pero no se trata de un conocimiento abstracto, sino desde el yo del escritor, que tiene que estar arraigado en su circunstancia, para permitir que el mundo que crea sea un mundo real. El mundo que aparece en la literatura no será real a no ser que esté "refractado por la sensibilidad", por la impresión que ha recibido un ser humano, el autor, que la pone por escrito para compartirla con otros y de ese modo compartir su conocimiento. Tiene que transmitir vida y eso solo puede hacerse si esa vida se ha vivido.

Dentro de su obra hay un elemento muy importante, del que habla desde el principio de Automoribundia y con una presencia constante en su vida y en su obra: la mujer. Pero la mujer como ser real, no esa construcción que la "vieja literatura" había creado:

La mujer de los otros, mojigatera y circunspecta, era una cosa convencional, dibujada por el almohadillaje artificioso de sus virtudes y sus cosas de en visita. Era la mujer metafísica. Amaba con lirismo y a distancia. Fraseaba demasiado y en las mejores ocasiones declamaba en vez de morder. Parecia no tener más que busto y aun ni busto siquiera $(68)^{6}$.

ARBOR CLXXXVI EXTRA JUNIO 2010 31-36 ISSN: 0210-1963

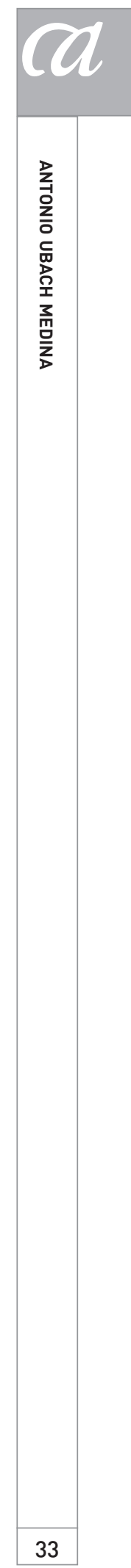


La presencia de la mujer se asocia a la de la vida pues es lo que permite sentir, y a través de ella se logra percibir el mundo. Dice de la nueva literatura: "Todos sus imperativos son carnales y todas sus cosas establecen una sensata y acuciadora correspondencia orgánica entre el mundo y el individuo" (71). A esto va unido el sentido del tiempo como presente permanente, que es otro punto de conexión con la vida: "Somos de nuestro momento y sería mentir nuestra naturaleza y aterirla y resabiarla, el creer otra cosa" (71). La raigambre en el mundo y en la vida pone de relieve lo que debería cambiar. La realidad social, y la realidad española en particular, tienen que estar presentes en la literatura.

\section{Colombine}

Sin duda, esa mujer que evoca en su intervención en el Ateneo la habia encontrado a partir del momento en que conoció a Carmen de Burgos. Como señala Concha Núñez (2005, 227-228), ambos dejan rastros de ese encuentro en sus respectivas obras de ese momento: Ramón en dos de sus colaboraciones en Revista Crítica, dirigida por Carmen, tituladas "La hija fea" (n. 6) y "Santa María la Blanca" (n. ${ }^{\circ}$ ); Carmen en la novela titulada El veneno del arte.

A partir de 1909 el nombre de Colombine aparece en Prometeo, la revista de Ramón. Una de las primeras ocasiones, en marzo de 1909, es la crónica que este hace del homenaje que organizó a Larra, en el que Carmen ocupó un lugar destacado, sentada al lado de la silla vacía que se había dejado en honor del autor romántico.

El número de julio de 1909 se abre con un artículo que lleva por título el pseudónimo de la escritora. En él Ramón hace una descripción que comienza así: "Colombine es una mujer inverosímil en esta tierra de mujeres a ultranza" (p. 1). Habla de su forma de ser, poniendo como ejemplo a todo tipo de personajes femeninos antiguos y modernos. $Y$ concluye: "Y sin embargo, no es ninguna de estas mujeres completamente [...] Se escapa a todas esas idiosincrasias y vive de todas" (p. 2). A continuación habla del salón de la calle Serrano donde se recluye a escribir. "Trabaja mucho, espontáneamente" (p. 2), dice. Lo retrata como un lugar lleno de objetos bellos. "Este salón es como una extensión de su regazo y él ampara y acoge con un afecto más allá del bien y del mal" (p. 3). Anuncia los proyectos próximos de la escritora, una nueva novela y un libro sobre Leopardi, el poeta italiano, del cual se reproduce un capítulo a continuación, y sobre ambos se desgranan elogiosas palabras.

La admiración por Carmen de Burgos no se centra, por tanto, solo en su relación sentimental, sino también en esa tarea común de escritores. "Escribieron durante años, frente a frente, más que diez juntos, con una fe que se alimentaba de dos voluntades y de un gran amor a la vida y a la literatura" (Núñez, 2005, 230).

Al mes siguiente, aparece en Prometeo un artículo de Colombine titulado "Autobiografía", que la autora empieza diciendo que escribe a petición del propio Ramón. Tras describir las formas que había pensado darle, se decide por la de la carta: "Así no sabré mentir". Comienza haciendo una descripción de su carácter: "Me río de la unidad del yo, porque llevo dentro muchos yoes..." Yoes que a veces se enfrentan entre sí.

Frente a la estabilidad que puede ser el ideal de muchos, y que ella ha deseado en alguna ocasión, acepta y disfruta de la complejidad de su existencia. Reconoce que ha sufrido y que se ha apasionado por diferentes causas, incluido el amor, pero confiesa su indiferencia actual por todo esto: "Lo hermoso es sentir la vida". Y desprecia los valores mundanos, a los que no está dispuesta a sacrificar su independencia.

Pasa a continuación a hablar de su vida, recordando su infancia y adolescencia en las tierras almerienses, en Rodalquilar, en contacto con la naturaleza. Esto lo considera algo importante en la formación de su carácter. $Y$ este lugar contrasta vivamente con la descripción negativa de su llegada a la ciudad. Repasa rápidamente los diversos avatares de la fortuna que se han ido sucediendo: "Y así, sufriendo y amando... entre lágrimas y goces se formó mi espiritu de hoy [...] Hoy solo creo en el arte y acepto el amor como bella mentira, una forma más perfecta de la amistad" (p. 43).

Habla de su trabajo como profesora doliéndose de la juventud perdida de las alumnas, que en vez de disfrutar de la vida se ven encerradas en las aulas. También de su trabajo como periodista, que le sirve para mostrar su indiferencia por la opinión de los que la juzgan: "... se me discute. ¡Qué honor! No se pondrán nunca de acuerdo ni yo me 
inquietaré por el fallo" (p. 44). Menciona sus traducciones, prólogos, etc., lo que considera una obra menor, "trabajo de hojarasca para ganar el sustento".

Sin embargo, "Hoy ya es otra cosa; empiezo mi labor". Se declara "naturalista romántica y variable como mis yoes", en búsqueda de la belleza a través de la literatura, principalmente de la novela, a la que proclama "la diosa de la Literatura". Habla de su libro de viajes, Por Europa, y de Cuentos de Colombine, como muestra de lo que puede llegar a hacer. Existe la probabilidad de que escriba más poesía, pero de lo que reniega definitivamente es del teatro: "Prefiero que me lea un imbécil a ver interpretar mis creaciones. Los cómicos son todos seres inferiores..." A continuación menciona su preferencia por la gente joven, frente a "los genios consagrados y los viejos dómines".

Acaba mencionando su vida familiar, su amor por su hija, y la variedad de sus actividades, desde la asistencia al Teatro Real a la visita a una ciudad minera o su labor en Melilla, como muestra de su independencia y de su falta de consideración por el qué dirán, con un final en el que advierte que esa misma noche podría describirse de otra manera. Un autorretrato que iba dirigido al público de la revista, pero sin duda también a quien se lo había pedido. $Y$, como se ve, que satisface muchas de las características enumeradas por Ramón.
Carmen y Ramón siguieron compartiendo durante muchos años su vida y su interés por la literatura nueva. Viajaron, conocieron lugares como Portugal o Italia, donde se sentían a gusto, escribieron en periódicos y revistas, apoyaron los proyectos de grupos de jóvenes a los que Ramón ya no pertenecía, Carmen siempre preocupada por las cuestiones sociales. Sin embargo, esta relación personal acaba a finales de 1929.

La hija de Colombine era actriz de no mucho éxito y con numerosos problemas tanto físicos como psicológicos. A finales de ese año, Gómez de la Serna consigue que se estrene su obra teatral titulada Los medios seres, y Carmen logra que su hija participe con un papel menor en la obra. Durante los ensayos, autor y actriz inician una relación (Ramón en sus memorias declara que ella lo sedujo) que durará menos de un mes, y que termina con una espantada de Ramón a París. "Esta vez, el golpe dio en el centro, superando toda la capacidad de resistencia de Carmen; se lo daban a la vez los dos seres que habian constituido toda su vida: el gran coloso que había sido siempre, enfrentado a toda adversidad, se tambaleó herido de muerte" (Núñez, 2005, 578).

Aunque se distanciaron, Carmen no dejó de considerar a Ramón como un amigo, valorando todos esos años transcurridos en un mismo afán. Habían sido veinte años de escritura y vida compartida, y de nuevo una lección de generosidad por parte de Carmen.

\section{NOTAS}

1 Concretamente, el 3 de julio.

2 Su padre pertenecía al partido liberal de Canalejas, fue diputado por un distrito andaluz que heredó de un pariente, Félix Gómez de la Serna, y ocupó la Dirección General de Registros; uno de sus tíos, Fernando Gómez de la Serna, fue ministro.

3 En Automoribundia relata, con cierta ironía, las consecuencias que tuvo la compra de un pan. El director le reprendió diciendo: "Sí, usted, que se ha permitido la osadía de llamar a la tahona de Gracián y ha comprado un pan, jun pan!, como si en el colegio lo matásemos de hambre" (Gómez de la Serna, 1948, 112). El tono burlesco con el que está contada esta anécdota muestra el rechazo del autor hacia el respeto a las apariencias y la hipocresía que ello supone.

4 Menciona a dos colaboradores: Ramos de Castro, "gran escritor después", y Pérez de Diego, "doctor de genial visión" (Gómez de la Serna, 1948, 120).

5 Más tarde escribirá una espléndida biografía sobre ella.

6 Las citas de este texto están tomadas de la versión que aparece en Gómez de la Serna, 1988, figurando la página entre paréntesis.

7 Agosto de 1909, pp. 40-46.

Aceptado: 7 de junio de 2010 


\section{BIBLIOGRAFÍA}

Brihuega, Jaime (1981): Las vanguardias artísticas en España. 1909-1936, Madrid, Istmo.

Gómez de la Serna, Ramón (1948): Automoribundia, vols. I y II, Madrid, Guadarrama, 1974.
Gómez de la Serna, Ramón (1988): Una teoría personal del arte. Antología de textos de estética y teoría del arte, ed. e intr. de Ana Martínez-Collado, Madrid, Tecnos.

Núñez Rey, Concepción (2005): Carmen de Burgos, Colombine, en la Edad de Plata de la literatura española,
Fundación José Manuel Lara, Sevilla.

Zlotescu, loana (1987): "El libro mudo, luz en los orígenes de Ramón Gómez de la Serna", intr. en Ramón Gómez de la Serna, El libro mudo, México, Madrid, Buenos Aires, F.C.E. 